\title{
Irradiation-induced molecular dipole reorientation in inverted polymer solar cell using small molecular electron collection layer
}

\author{
Zai-Quan Xu, ${ }^{1}$ Fu-Zhou Sun, ${ }^{1}$ Jian Li, ${ }^{1}$ Shuit-Tong Lee, ${ }^{2}$ Yan-Qing Li, ${ }^{1, a)}$ \\ and Jian-Xin Tang ${ }^{1, a)}$ \\ ${ }^{1}$ Jiangsu Key Laboratory for Carbon-Based Functional Materials \& Devices, Institute of Functional Nano \\ \& Soft Materials (FUNSOM), Soochow University, Suzhou 215123, China \\ ${ }^{2}$ Center Of Super-Diamond and Advanced Films (COSDAF) and Department of Physics and Materials Science, \\ City University of Hong Kong, Hong Kong SAR, China
}

(Received 17 September 2011; accepted 2 November 2011; published online 16 November 2011)

\begin{abstract}
Inverted polymer solar cell is developed using small molecular tris(8-hydroxyquinolinato) aluminum $\left(\mathrm{Alq}_{3}\right)$ as an electron collection layer between the active layer and indium-tin-oxide bottom cathode. Upon post-processing light irradiation by simulated solar illumination, the open-circuit voltage of the inverted device increases from $0.52 \mathrm{~V}$ to $0.60 \mathrm{~V}$, resulting in the enhancement of the power conversion efficiency from $2.54 \%$ to $3.33 \%$ with negligible change in the short-circuit current. The performance improvement is attributed to the removal of surface potential due to irradiation-induced molecular dipole reorientation in the $\mathrm{Alq}_{3}$ layer, which reduces the charge transport barrier and improves the charge collection efficiency. (C) 2011 American Institute of Physics. [doi:10.1063/1.3663548]
\end{abstract}

Bulk-heterojunction (BHJ) polymer solar cells (PSCs) based on a mixture of electron-donor conjugated polymer and electron-acceptor fullerene derivative have a positive potential to be the next-generation solar cell technologies due to low fabrication cost, highly mechanical flexibility, and large-area manufacturing feasibility. ${ }^{1-8}$ However, the power conversion efficiency (PCE) and long-term air stability are still the major challenges for PSCs being a commercially available technology. To achieve these goals, tremendous efforts have recently been devoted to improving the PSCs performance via the application of different materials, ${ }^{9-11}$ optimization of morphologies, ${ }^{5}$ and interface engineering of electrical contacts. ${ }^{12,13}$ In particular, inverted PSCs have been developed to overcome the rapid degradation in the regular-structure devices and to match the vertical phase separation in polymer BHJ. ${ }^{4,14-21}$ In an inverted PSC, the electron collection layer (ECL) sandwiched between the indium-tin-oxide (ITO) bottom cathode and the active layer is one of the most critical factors in determining device characteristics.

Previously, inorganic compound films such as titanium oxide (TiOx), ${ }^{15,16}$ zinc oxide $(\mathrm{ZnO}),{ }^{17,18}$ cesium carbonate $\left(\mathrm{Cs}_{2} \mathrm{CO}_{3}\right),{ }^{19,20}$ aluminum oxide $\left(\mathrm{Al}_{2} \mathrm{O}_{3}\right),{ }^{21}$ and atomic-layerdeposited cadmium sulfide $(\mathrm{CdS})^{14}$ have been incorporated as an ECL for inverted PSCs. However, a relatively hightemperature annealing process is required for solutionprocessed inorganic ECLs, which is incompatible with flexible substrates. $^{22}$ In this letter, the potential utilization of n-type small molecules for electron extraction in inverted PSCs is explored, which is easily fabricated with controlled film morphology and chemical composition at low processing temperature. An efficient inverted PSC with a blended poly (3hexylthiophene):[6,6]-phenyl C61 butyric acid methyl ester (P3HT:PCBM) active layer is achieved by integrating a ther-

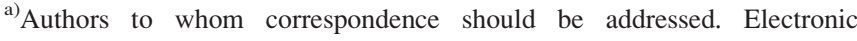
addresses: yqli@suda.edu.cn and jxtang@suda.edu.cn.
}

mally deposited layer of tris(8-hydroxyquinolinato) aluminum $\left(\mathrm{Alq}_{3}\right)$ as an $\mathrm{ECL} . \mathrm{Alq}_{3}$ is a representative electron transporting material used in organic light-emitting devices, and its chemical structure is shown in the inset of Fig. $1{ }^{23}$ Particularly, it has been demonstrated here that post-processing light irradiation with simulated air mass (AM) $1.5 \mathrm{G}$ solar illumination induces the increase of the open-circuit voltage $\left(\mathrm{V}_{\mathrm{OC}}\right)$ from $0.52 \mathrm{~V}$ to $0.60 \mathrm{~V}$, the increase of fill factor (FF) from $50 \%$ to $57 \%$, the decrease of series resistance $\left(\mathrm{R}_{\mathrm{S}}\right)$ from $90 \Omega$ to $35 \Omega$, and thereby the PCE enhancement from $2.54 \%$ to $3.33 \%$.

Inverted PSCs were fabricated on patterned ITO-coated glass substrates with a sheet resistance of $10 \Omega /$ sq. Upon a routine cleaning process, ${ }^{13,14}$ the ITO glass substrates were transferred to a vacuum deposition chamber with a base pressure of $2 \times 10^{-6}$ Torr for thermal evaporation of an $80 \mathrm{~nm}$-thick $\mathrm{Alq}_{3}$ layer. Deposition rate and thickness were monitored with a quartz oscillating crystal. Then, the resulting samples were transferred into a $\mathrm{N}_{2}$-filled glove box for the

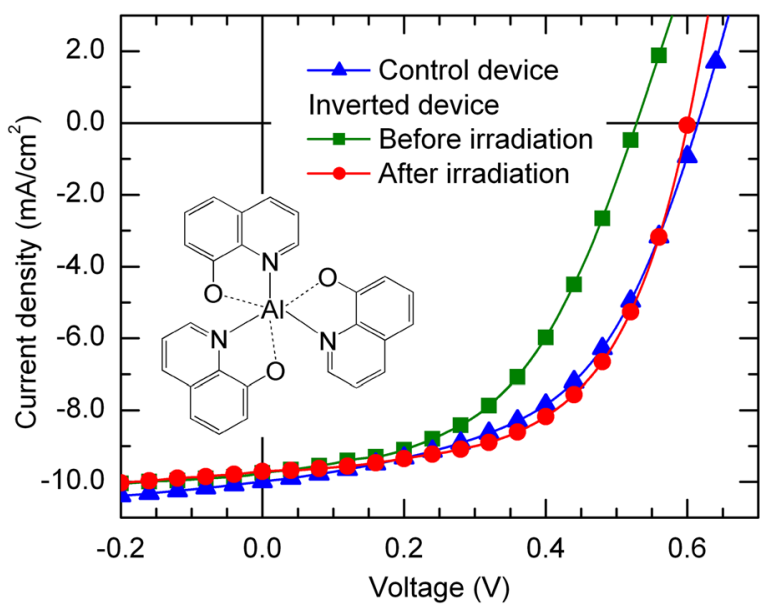

FIG. 1. (Color online) Current density-voltage (J-V) characteristics of the control and inverted PSCs under $100 \mathrm{~mW} / \mathrm{cm}^{2}$ AM $1.5 \mathrm{G}$ simulated solar illuminations before and after irradiation. Inset is the chemical structure of $\mathrm{Alq}_{3}$. 
spin-coating of the P3HT:PCBM photoactive layer from a 1:08 weight-ratio chlorobenzene-based solution $(20 \mathrm{mg} / \mathrm{ml})$ onto $\mathrm{Alq}_{3}$ coated ITO substrates, which was heated through a digitally controlled hot plate at $150^{\circ} \mathrm{C}$ for $30 \mathrm{~min}$ inside the glove box. The thickness of the resultant P3HT:PCBM blend film was determined to be approximately $120 \mathrm{~nm}$. Finally, the samples were transferred back to the vacuum deposition chamber for the thermal deposition of a 2 nm-thick molybdenum trioxide $\left(\mathrm{MoO}_{3}\right)$ hole-collection layer and a $100 \mathrm{~nm}$-thick $\mathrm{Al}$ anode. The active device area was $0.1 \mathrm{~cm}^{2}$ determined by the overlap of ITO cathode and Al anode. For comparison, a control device with a regular structure of ITO/ poly (3, 4-ethylenedioxythiophene):(polystyrene sulfonic acid) (PEDOT:PSS) (40 nm)/P3HT:PCBM (120 nm)/LiF (0.5 nm)/Al $(100 \mathrm{~nm})$ was also fabricated with the identical process parameters during the same batch processing. ${ }^{13}$ Photovoltaic measurements were conducted at room temperature in air without any device encapsulation. Details of the experimental setup have been given elsewhere. ${ }^{13,14}$

Figure 1 shows the current density-voltage $(\mathrm{J}-\mathrm{V})$ characteristics of the control device and the inverted PSC incorporating an $\mathrm{Alq}_{3}$ layer as the ECL under $\mathrm{AM} 1.5 \mathrm{G}$ simulated solar illumination of $100 \mathrm{~mW} / \mathrm{cm}^{2}$. As depicted in Figure 1, the as-fabricated inverted device exhibits a PCE of $2.54 \%$ with a $\mathrm{V}_{\mathrm{OC}}$ of $0.52 \mathrm{~V}$, a FF of $50 \%$, and a short-circuit current density $\left(\mathrm{J}_{\mathrm{SC}}\right)$ of $9.75 \mathrm{~mA} / \mathrm{cm}^{2}$. The results indicate that the $\mathrm{Alq}_{3}$ layer can provide the functionality for electron extraction and transport from the electron-acceptor material to the ITO cathode. However, it is noted in Fig. 1 that the $\mathrm{V}_{\mathrm{OC}}$ of the as-fabricated inverted PSC is lower than that of the control device, which is $0.61 \mathrm{~V}$.

To get additional insight into the device performance, the normalized incident photon-to-current conversion efficiency (IPCE) spectra of the inverted PSC with an $\mathrm{Alq}_{3} \mathrm{ECL}$ is compared with the control device. It is obvious in Fig. 2 that the inverted PSC with an $\mathrm{Alq}_{3}$ ECL exhibits a better performance in the wavelength ranging from $350 \mathrm{~nm}$ to $450 \mathrm{~nm}$. In order to investigate the enhancement in the IPCE spectra, optical absorption spectra of $\mathrm{Alq}_{3}$ and PEDOT:PSS on ITO substrates were examined. As shown in the inset of Fig. 2, enhanced absorption occurs in the range of $350 \mathrm{~nm}$ to

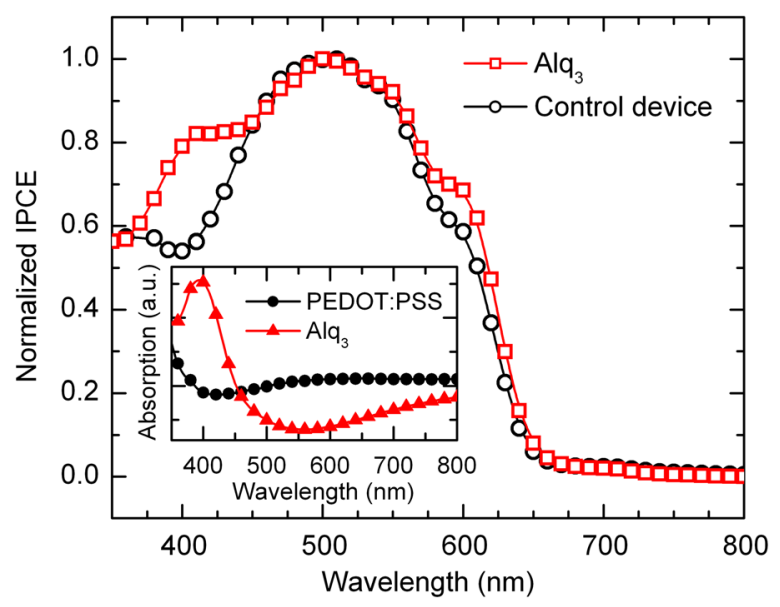

FIG. 2. (Color online) Normalized IPCE of the control device and inverted PSC under illumination. Inset is the UV-vis spectra of PEDOT:PSS and $\mathrm{Alq}_{3}$ on ITO glass substrates.
$450 \mathrm{~nm}$ for the $\mathrm{Alq}_{3}$ layer on ITO, indicating that the $\mathrm{Alq}_{3}$ layer also plays a role in the generation of photocurrent besides the P3HT:PCBM active layer.

However, it is evident in Fig. 1 that the identical PSC with an $\mathrm{Alq}_{3}$ ECL exhibits a significantly enhanced photovoltaic response upon continuous light irradiation by a 100 $\mathrm{mW} / \mathrm{cm}^{2}$ AM $1.5 \mathrm{G}$ simulated solar illumination for $40 \mathrm{~min}$. For instance, the $\mathrm{J}_{\mathrm{SC}}$ remains almost unchanged for the inverted PSC upon post-processing light irradiation, while the $\mathrm{V}_{\mathrm{OC}}, \mathrm{FF}$, and PCE are significantly enhanced to $0.60 \mathrm{~V}$, $57 \%$, and $3.33 \%$, respectively, which are comparable with those of the control device.

To obtain a better understanding of the effect of the post-processing irradiation, the correlation between the irradiation time and the device parameters of the inverted PSC with an $\mathrm{Alq}_{3}$ ECL is plotted in Fig. 3. As shown in Fig. 3(a), $\mathrm{V}_{\mathrm{OC}}$ and PCE show a similar trend with respect to the irradiation time by a $100 \mathrm{~mW} / \mathrm{cm}^{2}$ AM $1.5 \mathrm{G}$ simulated solar illumination. When the irradiation time increases, $\mathrm{V}_{\mathrm{OC}}$ and PCE are increased and approach saturated. In parallel with the increase in $\mathrm{V}_{\mathrm{OC}}$ and PCE, the light irradiation exhibits a negligible impact on the $\mathrm{J}_{\mathrm{SC}}$ as shown in the inset of Fig. 3(a). Additionally, the FF in Fig. 3(b) shows a notable enhancement from $50 \%$ to $57 \%$ as the irradiation time ranges from $0 \mathrm{~min}$ to $40 \mathrm{~min}$, whereas the $\mathrm{R}_{\mathrm{S}}$ decreases sharply from $90 \Omega$ to $35 \Omega$ during the irradiation process. It implies that the trend in $\mathrm{V}_{\mathrm{OC}}$ and FF with respect to irradiation time is related to the variation of $R_{S}$.
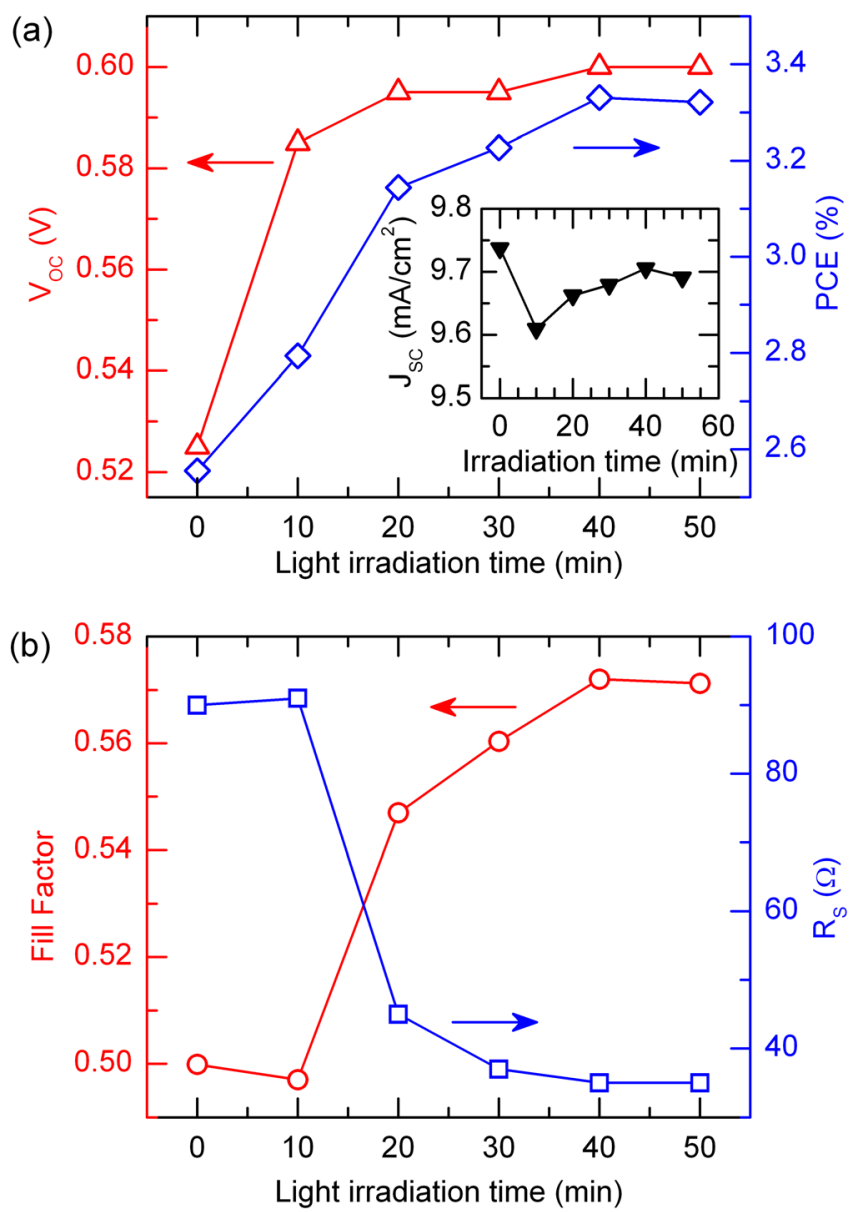

FIG. 3. (Color online) The evolution of $\mathrm{V}_{\mathrm{OC}}(\triangle), \mathrm{J}_{\mathrm{SC}}(\boldsymbol{\nabla})$, PCE $(\diamond)$, FF $(\bigcirc)$, and $R_{S}(\square)$ as a function of light irradiation time. 
(a)

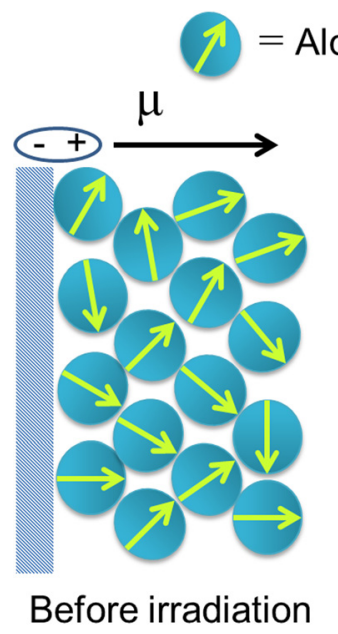

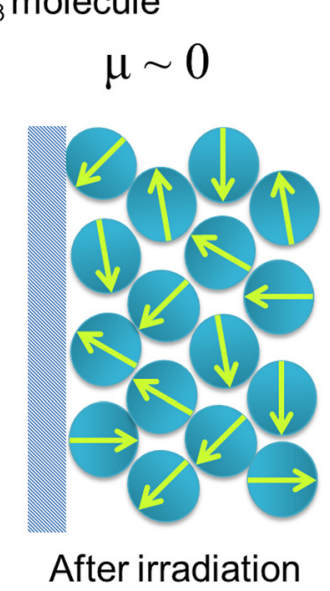

(b)
FIG. 4. (Color online) Schematic of the formation of giant surface potential of $\mathrm{Alq}_{3}$ film (a) before irradiation and (b) after irradiation.

The $\mathrm{Alq}_{3}$ molecules are known to have a permanent dipole moment, $\mu$, which is estimated to be 4.1D and 7.1D for meridional and facial isomers using density functional theory calculation, respectively. ${ }^{24}$ It has been demonstrated that the dipole moments of $\mathrm{Alq}_{3}$ molecules exhibit a preferential orientation with the positively charged surface upon vacuum deposition under dark conditions. ${ }^{24,25}$ As shown in Fig. 4(a), the molecular dipoles of $\mathrm{Alq}_{3}$ have some preference for a perpendicular orientation, although the molecules are distributed randomly in the $\mathrm{Alq}_{3}$ film. As a result, the buildup of the surface potential (SP) spontaneously occurs with the growth of $\mathrm{Alq}_{3}$ layer deposited in dark and increases linearly over a wide range of thickness. ${ }^{24,25}$ For example, the $\mathrm{SP}$ for vacuum-deposited $\mathrm{Alq}_{3}$ layer with a thickness of $560 \mathrm{~nm}$ was up to $28 \mathrm{~V}$ determined by the Kelvin probe method. ${ }^{25}$ Such a SP increases the barrier height for electron collection, and thus decreases the $\mathrm{V}_{\mathrm{OC}}$. However, as shown in Fig. 4(b), the molecular dipole orientation of $\mathrm{Alq}_{3}$ trends to be randomly distributed due to the electronic excitation of $\mathrm{Alq}_{3}$ molecules, and the giant SP can be almost completely removed due to depolarization of $\mathrm{Alq}_{3}$ molecules upon visible light irradiation, resulting in the reduction of SP. ${ }^{24,25}$ As a result, the $\mathrm{V}_{\mathrm{OC}}$ of an inverted PSC with an $\mathrm{Alq}_{3}$ ECL will be increased, which is very critical in forming an Ohmic contact according to previous literature. ${ }^{12}$ These unique findings imply an efficient approach to control the built-up surface potential by light irradiation, and even the $\mathrm{V}_{\mathrm{OC}}$ can be further enhanced by tuning the dipole orientation of other proper molecules instead of $\mathrm{Alq}_{3}$. Still, substantial future experimental work is required to understand these phenomena and their mechanisms.

In conclusion, we have demonstrated an efficient inverted PSC using an n-type organic layer of $\mathrm{Alq}_{3}$ as ECL.
Upon post-processing light irradiation by AM $1.5 \mathrm{G}$ simulated solar illumination, the PCE of the inverted device is enhanced from $2.56 \%$ to $3.33 \%$ with increased $\mathrm{V}_{\mathrm{OC}}$ and negligible change in the $\mathrm{J}_{\mathrm{SC}}$. The performance improvement is attributed to the removal of surface potential and reduced series resistance caused by favorable molecular dipole reorientation of the $\mathrm{Alq}_{3}$ ECL on ITO substrate upon light irradiation. These findings provide a facile method for realizing efficient inverted polymer solar cells with easy control of film properties.

The authors acknowledge the financial support by NSFC (Nos. 91027041, 61007020, 61107022, 61036009, 60937001), 973 program (No. 2010CB934502), the Natural Science Foundation of Jiangsu Province (No. BK2011280), and a Project Funded by the Priority Academic Program Development of Jiangsu Higher Education Institutions (PAPD).

${ }^{1}$ P. W. M. Blom, V. D. Mihailetchi, L. J. A. Koster, and D. E. Markov, Adv. Mater. 19, 1551 (2007).

${ }^{2}$ S. Günes, H. Neugebauer, and N. S. Sariciftci, Chem. Rev. 107, 1324 (2007).

${ }^{3}$ G. Dennler, M. C. Scharber, and C. J. Brabec, Adv. Mater. 21, 1323 (2009).

${ }^{4}$ L. M. Chen, Z. Hong, G. Li, and Y. Yang, Adv. Mater. 21, 1434 (2009).

${ }^{5}$ G. Li, V. Shrotriya, J. Huang, Y. Yao, T. Moriarty, K. Emery, and Y. Yang, Nat. Mater. 4, 864 (2005).

${ }^{6}$ L. H. Hoppe and N. S. Sariciftci, J. Mater. Chem. 16, 45 (2006).

${ }^{7}$ J. Y. Kim, K. Lee, N. E. Coates, D. Moses, T. Q. Nguyen, M. Dante, and A. J. Heeger, Science 317, 222 (2007).

${ }^{8}$ H. Y. Chen, J. H. Hou, S. Q. Zhang, Y. Y. Liang, G. W. Yang, Y. Yang, L. P. Yu, Y. Wu, and G. Li, Nat. Photonics 3, 649 (2009).

${ }^{9}$ N. Blouin, A. Michaud, D. Gendron, S. Wakim, M. Belletête, G. Durocher, Y. Tao, and M. Leclerc, J. Am. Chem. Soc. 130, 732 (2008).

${ }^{10}$ Y. Liang, Y. Wu, D. Feng, S. T. Tsai, H. J. Son, G. Li, and L. Yu, J. Am. Chem. Soc. 131, 56 (2009).

${ }^{11}$ N. Cho, H. L. Yip, S. K. Hau, K. S. Chen, T. W. Kim, J. A. Davies, D. F. Zeigler, and A. K. Y. Jen, J. Mater. Chem. 21, 6956 (2011).

${ }^{12}$ H. L. Yip, S. K. Hau, N. S. Baek, H. Ma, and A. K. Y. Jen, Adv. Mater. 20, 2376 (2008).

${ }^{13}$ Z. Q. Xu, J. Li, J. P. Yang, P. P. Cheng, J. Zhao, S. T. Lee, Y. Q. Li, and J. X. Tang, Appl. Phys. Lett. 98, 253303 (2011).

${ }^{14}$ J. J. Zhu, Z. Q. Xu, G. Q. Fan, S. T. Lee, Y. Q. Li, and J. X. Tang, Org. Electron. 12, 2151 (2011).

${ }^{15}$ R. Steim, S. A. Choulis, P. Schilinsky, and C. J. Brabec, Appl. Phys. Lett. 92, 093303 (2008).

${ }^{16}$ S. Sista, M. H. Park, Z. R. Hong, Y. Wu, J. H. Hou, W. L. Kwan, G. Li, and Y. Yang, Adv. Mater. 22, 380 (2010).

${ }^{17}$ T. Kuwabara, Y. Kawahara, T. Yamaguchi, and K. Takahashi, ACS Appl. Mater. Interfaces 1, 2107 (2009).

${ }^{18}$ J. Gilot, I. Barbu, M. M. Wienk, and R. A. J. Janssen, Appl. Phys. Lett. 91, 113520 (2007).

${ }^{19}$ H. H. Liao, L. M. Chen, Z. Xu, G. Li, and Y. Yang, Appl. Phys. Lett. 92, 173303 (2008).

${ }^{20}$ C. S. Kim, S. Lee, L. L. Tinker, S. Bernhard, and Y. L. Loo, Chem. Mater. 21, 4583 (2009).

${ }^{21}$ Y. Zhou, H. Cheun, and B. Kippelen, J. Mater. Chem. 20, 6189 (2010).

${ }^{22}$ F. C. Krebs, Sol. Energy Mater. Sol. Cells 93, 394 (2009).

${ }^{23}$ C. W. Tang and S. A. Van Slyke, Appl. Phys. Lett. 51, 913 (1987).

${ }^{24}$ H. Ishii, N. Hayashi, E. Ito, Y. Washizu, K. Sugi, Y. Kimura, M. Niwano, Y. Ouchi, and K. Seki, Phys. Status Solidi 201, 1075 (2004).

${ }^{25}$ E. Ito, Y. Washizu, N. Hayashi, H. Ishii, N. Matsuie, K. Tsuboi, Y. Ouchi, Y. Harima, K. Yamashita, and K. Seki, J. Appl. Phys. 92, 7306 (2002). 